\title{
Adaptive Cruise Control for vechile modelling using MATLAB
}

\author{
Ajeetha Apparna $\mathrm{G}^{1}$, Aishwarya $\mathrm{A}^{2}$ \\ ${ }^{1}$ St Joseph's College Of Engineering, \\ ${ }^{2}$ St Joseph's College Of Engineering,
}

\begin{abstract}
This paper proposes the P, PI, PID, IPDcomparison and analysis for full range of Adaptive Cruise Control System (ACC). ACC is the facultative cruise control for the vehicles that automatically adjusts the vehicle speed to maintain safe distance from host vehicle. Numerous control parameters like Kp,Ki,Kd are obtained by Ziegler -Nicholus method and Tyreus -Luybenmethod. In this paper various error criteria and time Domani specifications are compared to obtain better breaking performance. These methods are followed for different tuning $K p, K i, K d$ values for P, PI, PID and IPD structures for adaptive cruise control system using MATLAB.
\end{abstract}

Keywoed: Tyreus-luyben, Adaptive cruise control, Ziegler -nicholus

\section{Introduction}

Adaptive cruise control system is an advanced method of controlling the speed of the moving vehicle. It mainly reduces the driver's fatigue during long trip. By using this intelligent control one can easily control the speed of the car according to the prevailing situation. These types of sophistications are produced as embedded features in luxury cars. Adaptive cruise control system is made up of a sensor which is fitted to the moving vehicle which constantly notes the speed of the car and provides the input to the processing unit. A processing unit comprise a PID Controller. Initially the desired speed is set by the driver. This speed is known as the steady state value. The processing unit provides the output to the actuator according to the control action provided by PID controller. The actuator actuates the throttle pedal/brake to obtain the steady state value. A controller is designed according to the force exerted by the car to drive to a certain distance within a given time. It purely works on closed loop feedback control system. The speed of the response depends on the magnitude and steady state value is reached when a PID controller is used. Firstly a Proportional controller is used to decrease the rise time to a considerable value. Then in addition to that an Integral controller is used to improve the rise time but this should be taken care so that it does not destabilise the system. Finally a PID controller is designed to achieve the performance criteria thereby reducing the overshoot without affecting the dynamic response of the system. The oscillations produced by the controller is greatly reduced by adjusting the controlling parameters in order to achieve the steady state value. The values are simulated by using MATLAB software and several iterations are done inorder to achieve the desired speed control.

MODELING OF ADPATIVE CRUISE CONTROL SYSTEM

The physical modeling of the adaptive cruise control system is illustrated as shown in fig1

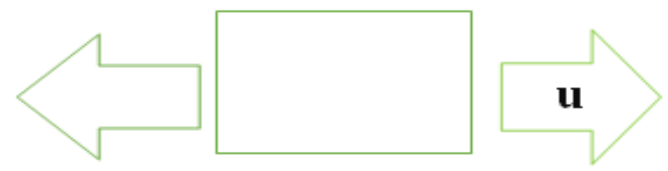

$\mathrm{u}=$ force generated on the road side and tire interface

$\mathrm{m}=$ mass

$\mathrm{u}=$ control force

$\mathrm{bv}=$ resistive force

$\mathrm{V}=$ vehicle velocity

In this vehicle modeling we consider that $\mathrm{u}$ can be controlled directly. Whereas, the dynamics of tires, powertrains, etc are 0 . Due to the external factors such as rolling resistance and wind drags varies linearly with the vehicle velocity $\mathrm{v}$ and accts in opposite direction of vehicle motion .

Transfer function :

$$
\frac{0.0144 e^{-0.001 s}}{s^{2}+0.018 s+0.006}
$$




\section{Controller design}

The objective of the cruise control system is to maintian the output speed of the system as set by inout signal based on command signal from the driver.Here single loop control system is considered which as been configured with non linear system. The controller function $\mathrm{Gc}(\mathrm{s})$ is designed to augment or modify the openloop function in a manner that produces the desired closed-loop performance characteristics. The plant functions $\mathrm{Gp}(\mathrm{s})$ represent the actuators and the controller part of the system, and the plant parameters are determined primarily by functional aspects of the control task.

\begin{tabular}{|l|l|l|l|l|l|l|}
\hline Controller & Kp & Ki & Kd & IE & IAE & ISE \\
\hline $\begin{array}{l}\text { PID with } \\
\text { disturbance }\end{array}$ & 7.2 & 13.5 & 0.96 & 0.00652 & 0.6003 & 0.3603 \\
\hline $\begin{array}{l}\text { PID } \\
\text { without } \\
\text { disturbance }\end{array}$ & 7.2 & 13.5 & 0.96 & 0.03035 & 0.4651 & 0.2164 \\
\hline
\end{tabular}

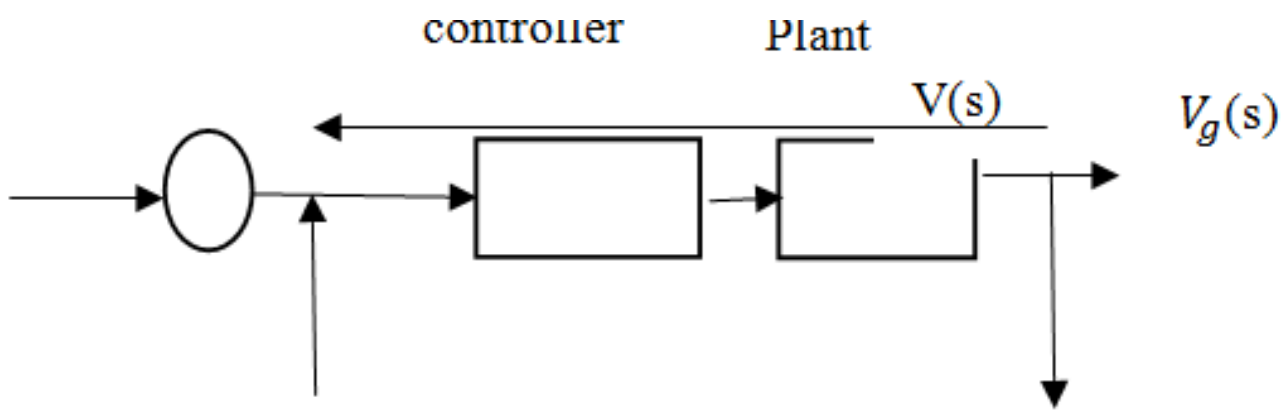

Fig 2: Cruise control system configuration

Mathematical equation for a PID controller is given by

$$
u(t)=K_{P} e(t)+K_{I} \int_{0}^{t} e(t) d T+K_{D} \frac{d e(t)}{d t}
$$

where,

$K_{P}, K_{I}$ and $K_{D}$ are the coefficients for proportional, integral and derivative terms.

$\mathrm{P}$ is responsible for current values of the error. I is responsible for past values of the error. $\mathrm{D}$ is responsible for possible future trends of the error based on its present rate of change.

\section{Ziegler Nicolous}

In this, the system is modelled using MATLAB to examine and find the parameters of PID controller. For both PID and IPD structure disturbance are provided and the output obtained from these disturbances are compared and the final results are obtained.Z-N tuning rules are inquisitive that helps to provides good values or 3 gain parameter. Thus, it helps us to determine the kp-controller gain value,Ti-the controllers integral gain, Tdthe controllers derivative gain.

\begin{tabular}{|l|l|l|l|l|l|l|}
\hline Controller & Kp & Ki & Kd & IE & IAE & ISE \\
\hline PID with disturbance & 7.2 & 13.5 & 0.96 & 0.00652 & 0.6003 & 0.3603 \\
\hline PID without disturbance & 7.2 & 13.5 & 0.96 & 0.03035 & 0.4651 & 0.2164 \\
\hline
\end{tabular}


This graphs shows the ZN PID structure, or which we obatinted the peak time,rise time and settling time. Zn pid with and without disturbance
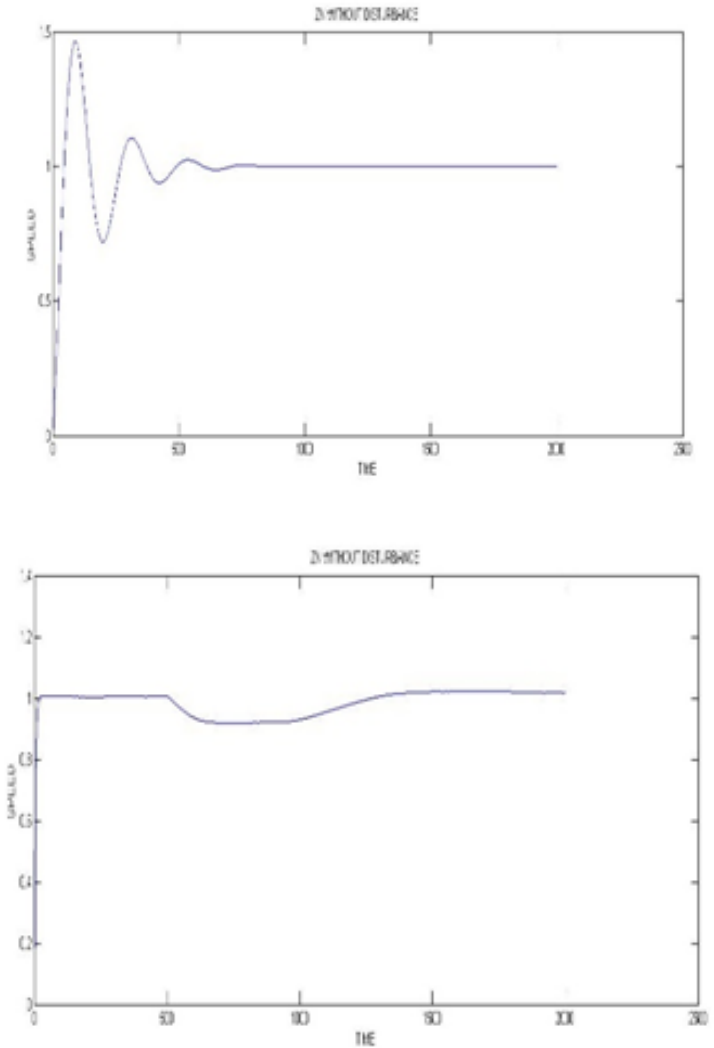

ZN PID without disturbance

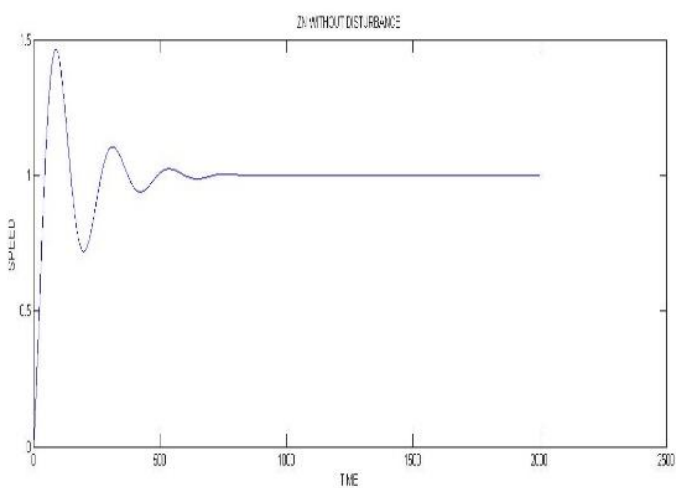

\section{ZN PID with disturbance}

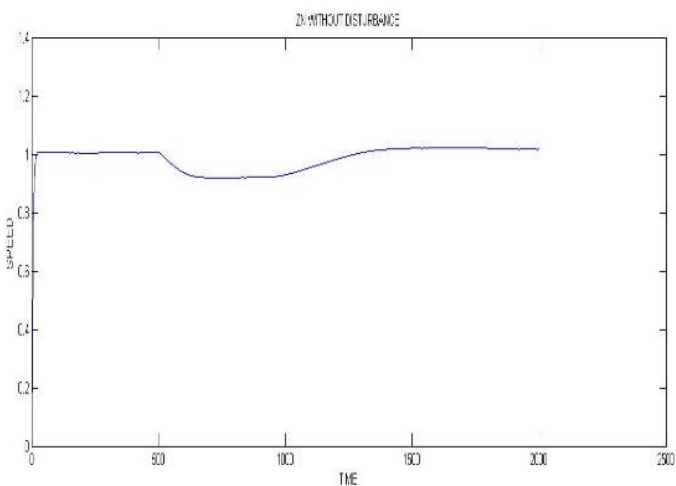

This graph shows the ZN IPD structure for which we obtained the peak time,risetime, and settling time. These values are specified and discussed in below table 
Table ZN PID time domain specifications

\begin{tabular}{|l|l|l|l|}
\hline Controller & $\begin{array}{l}\text { Settling } \\
\text { time(s) }\end{array}$ & $\begin{array}{l}\text { Rise } \\
\text { time(s) }\end{array}$ & $\begin{array}{l}\text { Peak } \\
\text { time(s) }\end{array}$ \\
\hline PID WITH & 27 & 1.9 & 2.8 \\
\hline PID WITHOUT & 4.2 & 1.9 & 10 \\
\hline
\end{tabular}

This table explains the time domain specifications which helps to define the system performance

\section{ZN IPD STRUCTURE}

All PID controller use the error signal as the input.Whereas, in PID structure it uses and I as the error signals and D sees the feedback signal only. Butwhen we use IPD controller it uses I as the error signal and PD as the feedback signals.

For PID we don't know the drawback of PID .When we use PID the output to jump around because the reference noise is feed into the proportional and especially the derivative terms. This high frequency output noise will excite higher order and unmodeled 'features' that will ruin the response. Ideally one wants to keep the control output smooth. This is why higher resolution feedback is important. These higherresolution feedback are provided by IPD structure.

The table below illustrates the $\mathrm{Kp}, \mathrm{Ki}, \mathrm{Kd}$ values obtained for IPD structures

Table ZN IPD Structure

\begin{tabular}{|l|l|l|l|l|l|l|}
\hline Controller & Kp & Ki & Kd & IE & IAE & ISE \\
\hline $\begin{array}{l}\text { IPD with } \\
\text { disturbance }\end{array}$ & 7.2 & 0.96 & 13.5 & 0.012 & 95.5 & 7.6 \\
\hline
\end{tabular}

\section{ZN IPD graph}

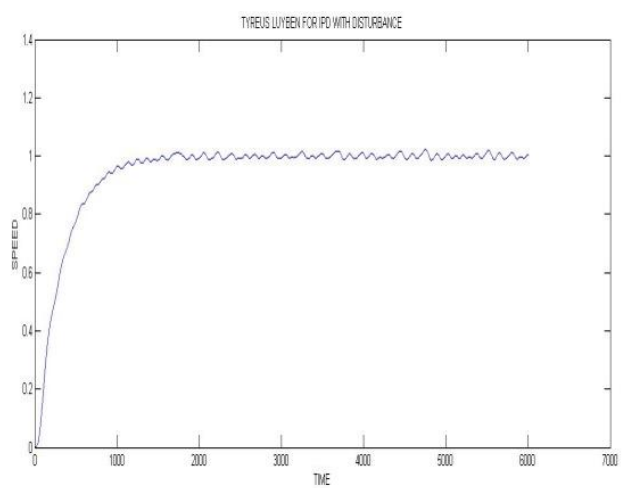

\section{Time Domain Specifications}

Table ZN IPD Time domain specifications

\begin{tabular}{|l|l|l|l|}
\hline Controller & $\begin{array}{l}\text { Settling } \\
\text { time(s) }\end{array}$ & $\begin{array}{l}\text { Rise } \\
\text { time(s) }\end{array}$ & $\begin{array}{l}\text { Peak } \\
\text { time(s) }\end{array}$ \\
\hline PID WITH & 99.8 & 4.9 & 88.5 \\
\hline
\end{tabular}

The above graph and table provides the values obtained by tuning the IPD for different value

\section{TYREUS LUYBEN METHOD}

It follows the same rules as ZN method but the final controller settings are different. These settings are based on ultimate gain values

The table below shows different values and error paramteres

\section{TyerusLuybenmethod}

\begin{tabular}{|l|l|l|l|l|l|l|}
\hline Controller & Kp & Ki & Kd & IE & IAE & ISE \\
\hline $\begin{array}{l}\text { PID with } \\
\text { disturbance }\end{array}$ & 5.45 & 0.165 & 12.9 & 0.0128 & 95.51 & 7.6 \\
\hline $\begin{array}{l}\text { PID without } \\
\text { disturbance }\end{array}$ & 5.45 & 0.165 & 12.9 & 0 & 2.377 & 7.437 \\
\hline
\end{tabular}




\section{TyreusLuyben without disturbance}

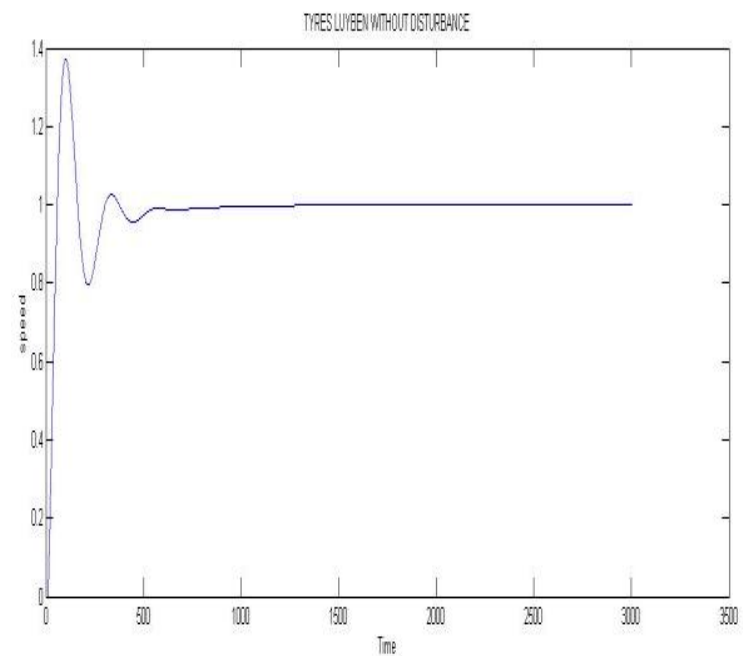

The graph obtained from the Simulink model provides the time domain specifications, with these we can obtain the greater results by comparing with it the $\mathrm{ZN}$ method, which is been discussed previously.

\begin{tabular}{|l|l|l|l|}
\hline Controller & Settling time (s) & Rise Time(s) & Peak Time(s) \\
\hline PID WITHOUT DISTURBANCE & 19.1 & 4.8 & 9 \\
\hline PID WITH DISTURBANCE & 5 & 2.7 & 4 \\
\hline
\end{tabular}

\section{TyreusLuyben with disturbances}

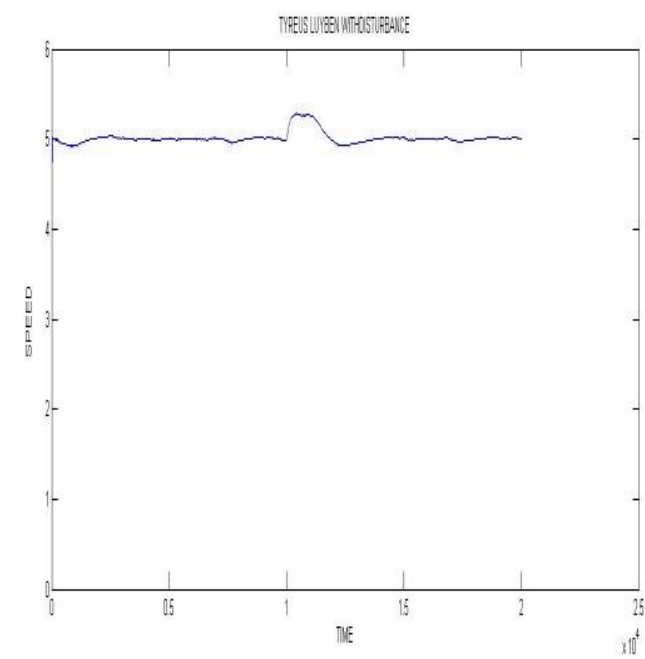

We have obtained the graph for PID with disturbance provided .

The below table shows the values obtained from these graphs

Time Domain Specifications

\section{TyreusLuyben IPD Structure}

Its same as the ZN IPD structure but the procedures at the end varies, they are discussed below The table values obtained are similar to those of $\mathrm{ZN}$ obtained before with the error values being more lesser.

The below provided graph is obtained by using the values of $\mathrm{kp}$,ki,andkd values which provides the major difference between the nomal PID obtained and IPD structure thus providing the higher and more defined output that the PID structure . 


\section{TyreusLuyben IPD structure graph}

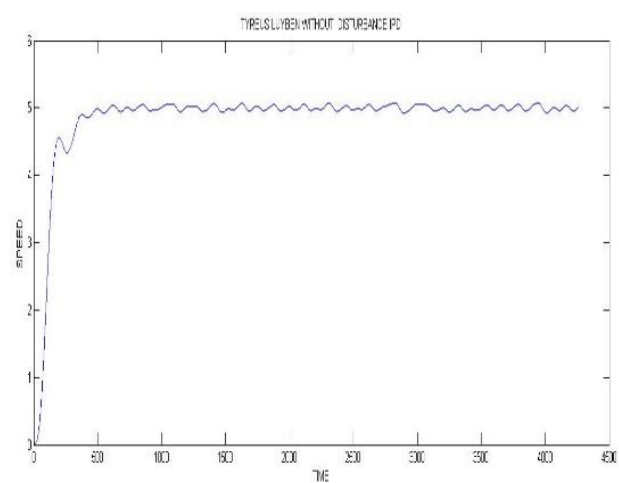

The above graph and table provides the values obtained by tuning the IPD for different values.

Table of TY IPD structure

\begin{tabular}{|l|l|l|l|l|l|l|}
\hline Controller & Kp & Ki & Kd & Error & IAE & ISE \\
\hline $\begin{array}{l}\text { IPD with } \\
\text { disturbance }\end{array}$ & 5.45 & 0.16 & 12.98 & 0.0128 & 95.51 & 7.6 \\
\hline
\end{tabular}

Time domain specification

\begin{tabular}{|l|l|l|l|}
\hline Controller & $\begin{array}{l}\text { Settling } \\
\text { time(s) }\end{array}$ & Rise time(s) & $\begin{array}{l}\text { Peak } \\
\text { time(s) }\end{array}$ \\
\hline $\begin{array}{l}\text { IPD WITH } \\
\text { DISTURBANCE }\end{array}$ & 79.2 & 1.8 & 2.4 \\
\hline
\end{tabular}

\section{Results And Discussions}

The PID and IPD controller's structures has been employed for the vehicles in cruise control model in the simulation. The actual speed is being measured and its been modelled in the Simulink. This is being allowed to interact and sent back to the controller after the measured speed. Here the interaction is provided with a negative feedback, such that it subtraction process obtains between the desired speed anactual speed.

Table Time Domain Specifications

\begin{tabular}{|c|c|c|c|}
\hline Controller & IAE & ISE & Error \\
\hline $\begin{array}{l}\mathrm{ZN} \\
\text { withdisturbance }\end{array}$ & 0.6003 & 0.00652 & 0.00652 \\
\hline ZN PID without & 0.4651 & 0.2164 & $\mathbf{0 . 0 3 0 3 5}$ \\
\hline $\begin{array}{l}\mathrm{ZN} \text { ipd without } \\
\text { disturbance }\end{array}$ & 95.1 & 7.6 & 0.00128 \\
\hline $\begin{array}{lrl}\mathrm{ZN} & \text { IPD } & \text { with } \\
\text { disturbance }\end{array}$ & 93.1 & 7.4 & 0.00507 \\
\hline $\begin{array}{lr}\text { TY PID } & \text { with } \\
\text { disturbance }\end{array}$ & 95.51 & 7.6 & 0.0128 \\
\hline TY PID without & 2.377 & 7.437 & $\mathbf{0}$ \\
\hline TY IPD with & 2.241 & 5.025 & -0.036 \\
\hline TY IPD without & 2.377 & 5.6501 & $\mathbf{0}$ \\
\hline
\end{tabular}

Table Error specifications

\begin{tabular}{|l|l|l|l|}
\hline Controller & $\begin{array}{l}\text { Rise } \\
\text { Time(s) }\end{array}$ & $\begin{array}{l}\text { Peak } \\
\text { Time(s) }\end{array}$ & $\begin{array}{l}\text { Settling } \\
\text { Time(s) }\end{array}$ \\
\hline $\begin{array}{l}\text { ZN PID } \\
\text { withdisturbance }\end{array}$ & 1.9 & 2.8 & 27 \\
\hline ZN PID without & 1.9 & 4.2 & 10 \\
\hline $\begin{array}{l}\text { ZN ipd without } \\
\text { disturbance }\end{array}$ & 99.8 & 4.9 & 88.5 \\
\hline $\begin{array}{l}\text { TY PID with } \\
\text { disturbance }\end{array}$ & 2.7 & 4 & 5 \\
\hline TY PID without & 4.8 & 9 & 19.1 \\
\hline TY IPD without & 79.2 & 1.8 & 2.4 \\
\hline
\end{tabular}


The results obtained by combining the results of ZN PID method, TY PID method ,TY IPD structure. The graph obtained is given below

\section{Erorr specifications}

The combined graph obtained is shown below

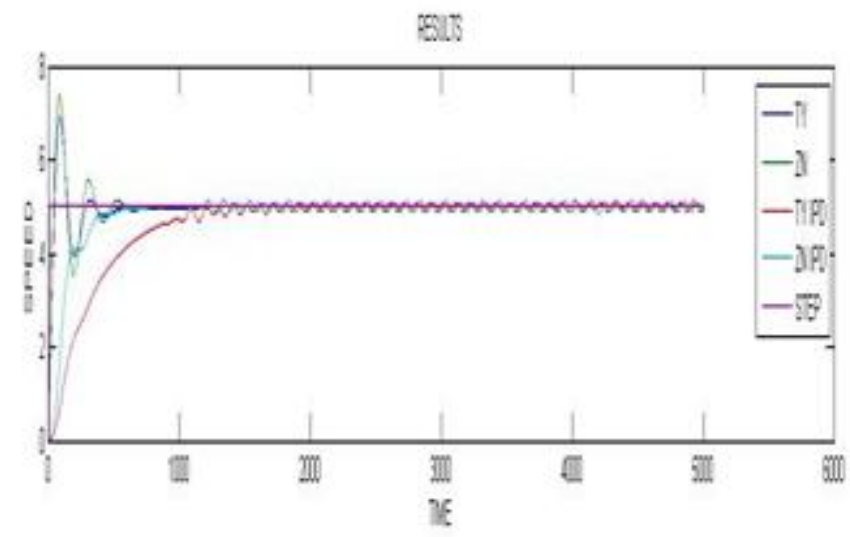

\section{Conclusions}

In the below section we widely discuss about the time domain and error specifications and to conclude the better results

In this section simulations modules are discussed those demonstrate the wide applicability in the cruise controller. Where this paper covered an overview PID,IPD controller structure and they are designed using ZN and tyreus method .The simulation results obtained for ZN and TY are compared and discussed. ZN PID with disturbance had the higher settling point, wherein, TY PID with disturbance had lower settling point thus they get settled within shorth period of time. The other error paramters are been considered and examined those says that TY PID and TY IPD are without any error qualitives and also the integral abosulute error and the integral square error are also been taken that helps to calculate the mathematical errors in the Simulink module .The integral absolute error and square errors are lesser in ZN PID .

\section{Reference}

[1]. International Conference on Information Engineering, Management and Security 2015 [ICIEMS 2015]

[2]. V. V Sivaji, Dr. M. Sailaja,Adaptive Cruise Control Systems for Vehicle Modeling Using Stop and Go Manoeuvres,International Journal of Engineering,Research and Applications, Vol3 Issue4 ,JulAug 2013.

[3]. Rohan Kumar and Rajan Pathak ,2012, Adaptive Cruise Control - Towards a Safer Driving Experience, International Journal of Scientific and Engineering Research Volume 3, Issue 8, August2012.

[4]. Modeling and design of cruise control system with feedforward for all terrian vehicles khaledsailan and klaus.dieter Kuhnert

[5]. Thanah hung tran modeling and contol of unmanned Ground Vehicle .Phd thesis september 2007 